\title{
Usefulness of two clinical (CBC and PETHEMA) scores for predicting early death in patients with acute promyelocytic leukemia: A single-center study in Mexico City
}

\author{
Christian O. Ramos-Peñafiel ${ }^{1 *}$, Efreen Montaño-Figueroa ${ }^{1}$, Humberto Castellanos-Sinco ${ }^{1,2}$, \\ Irma Olarte-Carrillo ${ }^{3}$, Adrian Santoyo-Sánchez ${ }^{1}$, Etta Rozen-Fuller ${ }^{1}$, Gilberto Barranco-Lampon ${ }^{1}$, \\ Juan F. Zazueta-Pozos ${ }^{1}$ and Adolfo Martínez-Tovar ${ }^{3}$
}

${ }^{1}$ Servicio de Hematología, Hospital General de México “Dr. Eduardo Liceaga”; ${ }^{2}$ Servicio de Hematología, Hospital General de Zona, Unidad Medicina Familiar (UMAA), No. 48 "San Pedro Xalpa", Instituto Mexicano del Seguro Social; ${ }^{3}$ Laboratorio de Biología Molecular, Hospital General de México "Dr. Eduardo Liceaga". Mexico City, Mexico

\begin{abstract}
Background: The use of all-transretinoic acid together with chemotherapy has improved the prognosis of patients with acute promyelocytic leukemia (APL). However, less than 20\% still die prematurely, mainly from hemorrhage. Objective: The objective of this study was to identify the utility of the PETHEMA score and complete blood count (CBC) score for the detection of patients with APL at risk of premature death. Materials and methods: A retrospective observational study in patients with de novo APL treated between 2001 and 2015 at Hospital General de México. Results: Among the 79 patients studied, the mean age was 35 years (17-57 years). According to the PETHEMA score, most patients were deemed low risk ( $n=34$ $42.5 \%)$ followed by high-risk $(n=25,31 \%)$ and intermediate-risk patients ( $n=21,26.3 \%)$. As per the CBC score, $16.3 \%$ $(n=13), 31.3 \%(n=25)$ and $52.5 \%$ of patients $(n=42)$ were considered as low-risk (0 points), intermediate-risk (1 and 2 points), and high-risk patients, respectively (3 points). Overall survival at 5 years was $73 \%$, with a lower rate in those patients considered as high risk for the two scales. Individually, both thrombocytopenia and elevated fibrinogen levels were associated with premature death. Conclusion: The PETHEMA score, like the CBC score, allows for the identification of patients at risk of premature death, with as thrombocytopenia is an independent risk factor.
\end{abstract}

Key words: Acute promyelocytic leukemia. Survival analysis. Prognosis.

\section{Introduction}

Acute promyelocytic leukemia (APL) is a neoplasm characterized by the blockage of myeloid cell differentiation mainly secondary to $t(15 ; 17)$ (q24.1; q21.2) ${ }^{1}$. Its prevalence is high in Latin America and the Caribbean? Studies conducted in the United States (California and
Florida) have identified that its frequency is higher in the Latino population compared to Anglo-Saxons (24.3\% vs. $8.3 \%$ ) or even African-Americans ${ }^{3,4}$. Unlike other types of leukemia, treatment is highly effective and based on the use of all-transretinoic acid (ATRA) which allows for the differentiation of promyelocytes to granulocytes ${ }^{5,6}$ Various cooperative groups worldwide (PETHEMA,
Correspondence:

*Christian O. Ramos-Peñafiel

E-mail: leukemiachop@ hotmail.com
Available online: 17-10-2019 Rev Med Hosp Gen Mex. 2019;82(4):187-193

www.hospitalgeneral.mx under the CC BY-NC-ND license (http://creativecommons.org/licenses/by-nc-nd/4.0/). 


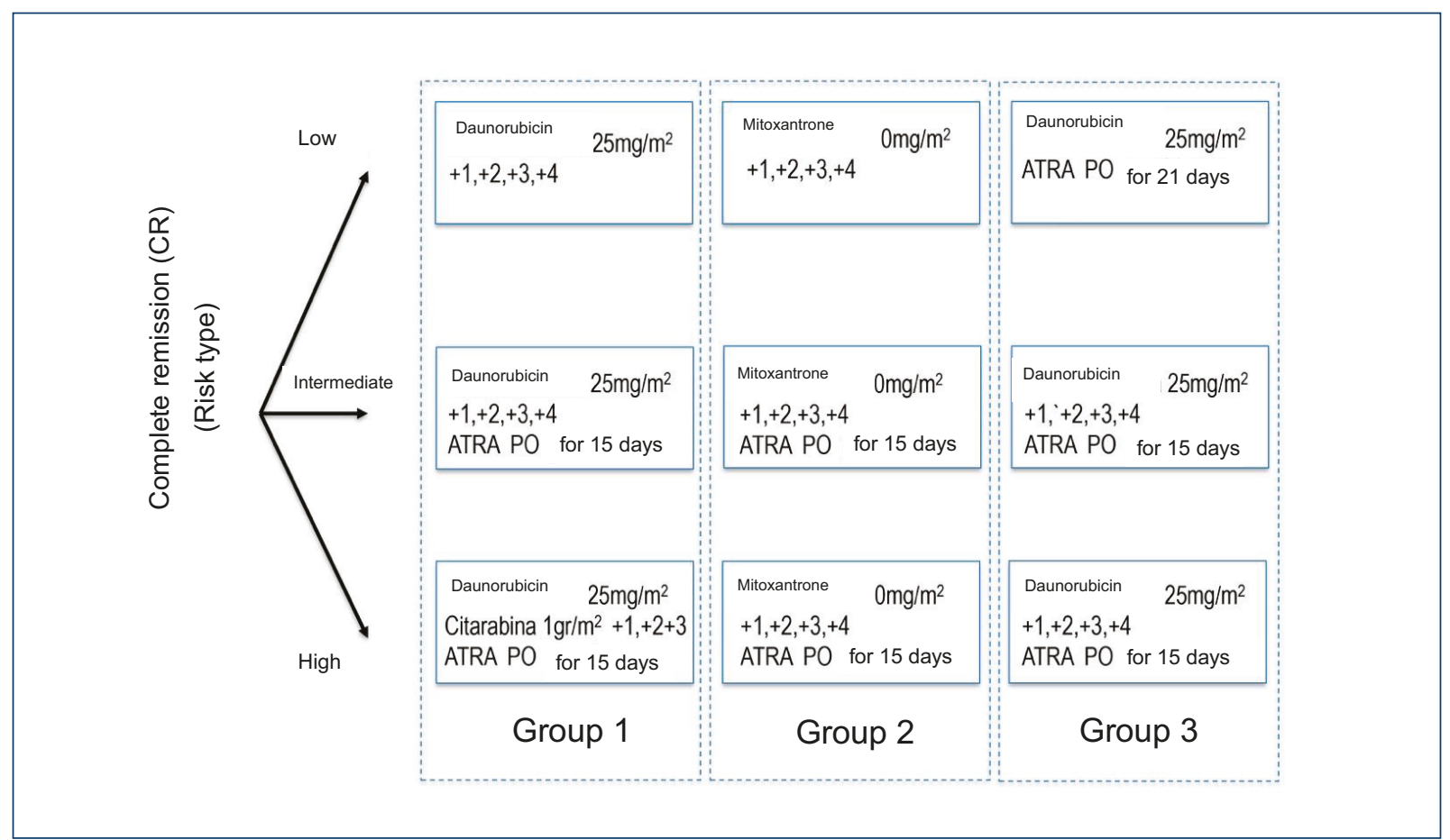

Figure 1. Risk-based consolidation scheme, the risk was established according to the PETHEMA score.

GIMEMA, and HOVON) have identified that the most effective combination during induction is with some type of anthracycline (Daunorubicin [DAU] or Idarubicin) and more recently with arsenic trioxide (ATO) ${ }^{7-11}$. For Latin America, the International Consortium on APL (IC-APL) recommends the use of DAU mainly due to its easy access and safety profile ${ }^{12}$. Recently, Crespo-Solis et al. published the experience of using an adaptation of the IC-APL guidelines, in a health center in Mexico City, reaching a $94.4 \%$ complete remission $(\mathrm{CR})$ rate and $89.1 \%$ overall survival rate ${ }^{13}$. Despite the high response rate, less than $20 \%$ of patients die prematurely, mostly due to hemorrhages ${ }^{14}$. Unfortunately, mortality is still high, especially in countries with poor access to ATRA and in patients considered as high-risk patients ${ }^{15-17}$. This risk (low, intermediate, and high) is established using the classification of the Spanish group PETHEMA (Spanish Program on Hematology Treatments) which is based on the combination of two variables; leukocyte count and platelet count, considering those cases with values above $10 \times 10^{9} / \mathrm{L}$ leukocytes such as high-risk patients ${ }^{18,19}$. An increasing number of factors have been assimilated to identify high-risk patients. The main ones are at the molecular level (FLT3-ITD mutation) and flow cytometry (CD56, CD2, and CD34) ${ }^{20,21}$. To improve the clinical scale, Park et al. included hemoglobin values into the risk score, known as complete blood count (CBC) score, and unlike the PETHEMA score, the risk was established with the sum of each of the different values ${ }^{22}$ The main objective of this study was to identify the utility of the two scales (PETHEMA and CBC score) on the risk of premature death of patients with APL undergoing an ATRA and DAU-based treatment as induction therapy.

\section{Materials and methods}

\section{Study design}

A retrospective, observational study in patients diagnosed with de novo APL treated at the Hematology Department of Hospital General de México from January 2001 to June 2015.

\section{Treatment protocol}

\section{INDUCTION}

ATRA was administered for 45 days at a dose of 10 $\mathrm{mg} / 10 \mathrm{~kg}$ of body weight, together with DAU at a dose of $45 \mathrm{mg} / \mathrm{m}^{2}$ of body surface area on days $+2,+4,+6$, and +8 .

\section{Consolidation}

Three monthly blocks were used, according to the type of risk. ATRA was added to the treatment of intermediate- or high-risk patients. The consolidation scheme is described in figure 1. 


\section{Maintenance}

Maintenance lasted for 2 years, based on 6-mercaptopurine at a dose of $50 \mathrm{mg} / \mathrm{m}^{2}$ administered orally on a daily basis and $50 \mathrm{mg}$ intramuscular methotrexate on a weekly basis. Administration of ATRA took place every 3 months for a period of 15 days.

Dexamethasone $8 \mathrm{mg}$ was added preventively to the treatment of high-risk patients 3 times a day. In case of suspicion of differentiation syndrome, ATRA administration was suspended until improvement of symptoms.

\section{RISK SCALES}

Under the PETHEMA classification, high risk was considered: leukocytes $\geq 10 \times 10^{9} / \mathrm{L}$; intermediate risk: leukocytes < $10 \times 10^{9} / \mathrm{L}$ and/or platelets $\leq 40 \times 10^{9} / \mathrm{L}$; and low risk if leukocytes $<10 \times 10^{9} / \mathrm{L}$ and/or platelets $>40 \times 10^{9} / L^{18,19}$.

The $\mathrm{CBC}$ scoring system assigns 1 point to each variable: leukocytes $\geq 10 \times 10^{9} / \mathrm{L}$, platelets $\leq 40 \times 10^{9} / \mathrm{L}$, hemoglobin $\leq 8 \mathrm{~g} / \mathrm{dL}$; and the level of risk is due to the sum of points: low ( 0 points), intermediate (1 point), and high (2-3 points).

\section{Statistical analysis}

Data were analyzed with IBM SPSS statistical software, version 20.0. For the analysis of the prognostic impact of the scores as well as the different variables on mortality, a multivariate analysis was performed, identifying the risk $(\mathrm{OR})$ for each risk variable. Survival curves were obtained by the Kaplan-Meier method. The results whose hypothesis contrast test yielded $p \leq 0.05$ were deemed statistically significant.

\section{Ethical considerations}

All patients were provided with informed consent by the institution for the administration of treatment as well as for the administration of transfusion support.

\section{Results}

From January 2001 to June 2015, 82 patients with APL were analyzed and included in the institutional protocol, HGMLAP-2001. Only three cases were excluded, due to the lack of information for the final analysis. ATRA administration was initiated early in all patients accompanied by transfusion support.
Table 1. Qualitative features of patients with APL treated at Hospital General de México between 2001 and 2015

\begin{tabular}{|l|c|}
\hline Feature & n (\%) \\
\hline Total patients & 79 \\
\hline $\begin{array}{l}\text { Gender } \\
\text { Males }\end{array}$ & \\
Females & $33(41.8)$ \\
\hline Clinical manifestations & $46(58.2)$ \\
\hline ATRA syndrome & \\
Febrile neutropenia & $12(15.2)$ \\
Mild hemorrhage & $50(63.3)$ \\
Moderate-severe hemorrhage & $27(34.2)$ \\
Central nervous system hemorrhage & $48(60.8)$ \\
\hline PETHEMA score & $4(5.1)$ \\
\hline Low risk & \\
Intermediate risk & $19(24.1)$ \\
High risk & $36(45.6)$ \\
\hline CBC score & $24(30.4)$ \\
\hline Low risk (0 points) & \\
\hline Intermediate risk (1 point) & $12(15.2)$ \\
\hline High risk (2 and 3 points) & $27(34.2)$ \\
\hline
\end{tabular}

APL: acute promyelocytic leukemia; CBC: complete blood count.

\section{Patient's characteristics}

Among the 79 eligible patients, $58.2 \%$ were female ( $n=46$ ); the average age was 34 years (range 17-57 years). Only $10 \%$ of patients were older than 50 years at the time of diagnosis.

The mean white blood cell count at diagnosis was $14.54 \times 10^{9} / \mathrm{L}$ (range $0.38-204 \times 10^{9} / \mathrm{L}$ ), but the majority were with $<10 \times 10^{9} / \mathrm{L}(69.6 \%), 11.3 \%$ of the cases showed values above $50 \times 10^{9} / \mathrm{L}$ at the time of diagnosis. The mean platelet volume was $39.21 \times 10^{9} / \mathrm{L}$ (range 4-272 × 109/L); being mostly < $50 \times 10^{9} / \mathrm{L}(73.8 \%)$.

The main clinical manifestation at diagnosis was hemorrhage followed by anemic syndrome. No splenomegaly or nodal growth was documented in any patient Among the 80 eligible cases, only $3.8 \%(n=3)$ presented a creatinine value above $1.5 \mathrm{mg} / \mathrm{dL}$ at diagnosis and $7.5 \%(n=6)$ presented bilirubin levels $>2 \mathrm{mg} / \mathrm{dL}$ isolated or in conjunction with elevated aspartate aminotransferase or alanine transaminase levels.

The qualitative and quantitative features of the studied population are described in tables 1 and 2, respectively.

\section{Classification according to risk}

Table 1 shows the number of patients classified in each risk level according to the PETHEMA scales and CBC score. 
Table 2. Quantitative features of patients with APL treated at Hospital General de México between 2001 and 2015

\begin{tabular}{|c|c|c|}
\hline Analyte & Mean (range) & $\begin{array}{l}\text { Standard } \\
\text { deviation }\end{array}$ \\
\hline Age (range) & $34(17-57)$ & \pm 11.8 \\
\hline $\begin{array}{l}\text { Leukocytes }\left(\times 10^{9} / \mathrm{L}\right) \\
\mathrm{n} \text { cases with }<10(\%) \\
\mathrm{n} \text { cases with } \geq 10(\%)\end{array}$ & $\begin{array}{c}14.54(0.38-204) \\
55(69.6) \\
24(30.4)\end{array}$ & \pm 30.18 \\
\hline $\begin{array}{l}\text { Hemoglobin }(\mathrm{g} / \mathrm{dL}) \\
\mathrm{n} \text { cases with } \leq 8(\%) \\
\mathrm{n} \text { cases with }>8(\%)\end{array}$ & $\begin{array}{c}8.79(3.3-17.9) \\
51(64.6) \\
28(35.4)\end{array}$ & \pm 2.8 \\
\hline $\begin{array}{l}\text { Platelets }\left(\times 10^{9} / \mathrm{L}\right) \\
\text { n cases with } \leq 40(\%) \\
\text { n cases with }>40(\%)\end{array}$ & $\begin{array}{l}39.21(4-272) \\
54(68.4) \\
25(31.6)\end{array}$ & \pm 47.15 \\
\hline Albumin $(\mathrm{g} / \mathrm{dL})$ & $3.5(1.8-5.1)$ & \pm 0.6 \\
\hline AST (UI/L) & $33.8(10-141)$ & \pm 25.6 \\
\hline ALT (UI/L) & $35.1(10-117)$ & \pm 24.6 \\
\hline Alkaline phosphatase (UI/L) & $88.7(35-371)$ & \pm 52.4 \\
\hline Lactate dehydrogenase (UI/L) & $327(100-1272)$ & \pm 211.5 \\
\hline Bilirubin $(\mathrm{mg} / \mathrm{dL})$ & $0.99(0.32-5.4)$ & \pm 0.72 \\
\hline Creatinine $(\mathrm{mg} / \mathrm{dL})$ & $0.79(0.3-1.6)$ & \pm 0.25 \\
\hline Urea (mg/dL) & $30.05(6.4-76.3)$ & \pm 13.09 \\
\hline PT (s) & $14.9(11.3-25.9)$ & \pm 2.7 \\
\hline aPTT (s) & $26.3(18.2-49.8)$ & \pm 4.9 \\
\hline $\mathrm{TT}(\mathrm{s})$ & $22.4(12-117)$ & \pm 13.7 \\
\hline Fibrinogen $(\mathrm{g} / \mathrm{dL})$ & $227.1(0-671)$ & \pm 129.6 \\
\hline
\end{tabular}

PT: prothrombin time; aPPT: activated partial thromboplastin time; TT: thrombin time; APL: acute promyelocytic leukemia; ALT: alanine transaminase; AST: aspartate aminotransferase.

\section{Treatment response}

The rate of CRs was $74.7 \%$ of cases $(n=59)$, with a therapeutic failure of $25.3 \%$ of cases $(n=20)$. During induction therapy, $62.5 \%$ of patients $(n=50)$ developed febrile neutropenia, with $16 \%$ of patients $(n=8)$ dying from sepsis.

The differentiation syndrome was perceived in $15 \%$ of patients $(n=12)$, with 3 patients $(3.8 \%)$ dying from this complication.

\section{Survival}

At a mean follow-up of 2.8 years (112 days-13.4 years), the overall survival rate was $76 \%$. The overall mortality rate was $25.3 \%(n=21)$. When analyzing the survival rate according to each of the risk groups, the patients considered as low risk by the PETHEMA scale showed a higher survival rate $(86 \%)$ compared to those highrisk patients $(58 \%)$. When analyzing the survival rate according to the CBC score, patients without any risk score showed a higher survival rate $(92 \%)$, unlike those patients who scored different risk factors $(60 \%$ in those patients with three points). Survival according to each of the PETHEMA and $C B C$ risk groups is described in figure 2 .

\section{Factors associated with mortality}

Individually, severe thrombocytopenia ( $\left.<40 \times 10^{9} / \mathrm{L}\right)$ as well as prolonged thrombin time behaved as a risk factor for death, but elevated serum fibrinogen levels also behaved as an independent risk factor for premature and late death. Both PETHEMA and CBC scores behaved as a global risk factor, but the latter allowed patients to be better distinguished. Table 3 describes the risk value of the different variables for both premature and late death.

\section{Association between CBC and PETHEMA score}

When analyzing the risk groups, most patients were in the intermediate-risk group $(n=36,45.6 \%)$ followed by the high-risk group $(n=24,30.4 \%)$ in the PETHEMA score. However, when searching for the correlation between the two scales, the patients considered as low or high risk for the PETHEMA score had 0-3 factors for the CBC score, respectively. A greater discrepancy was registered in those patients who had between one and two risk factors, as they were distributed between the intermediate- and high-risk group of the PETHEMA score, respectively.

\section{Discussion and conclusions}

APL is a major hematological emergency, due to its high risk of death at the time of diagnosis due to a hemorrhagic event. Early administration of ATRA together with intensive transfusion support is the main strategies for reducing mortality ${ }^{23}$. Mortality associated with leukemia was lower compared to our historical record, mainly occurring in high-risk patients.

When comparing the two scales, similarity was only identified in the low-risk groups (low-risk PETHEMA or patients with zero CBC score, that is, without relevant biochemical alterations) as cases were identified in the group of intermediate-risk patients with 

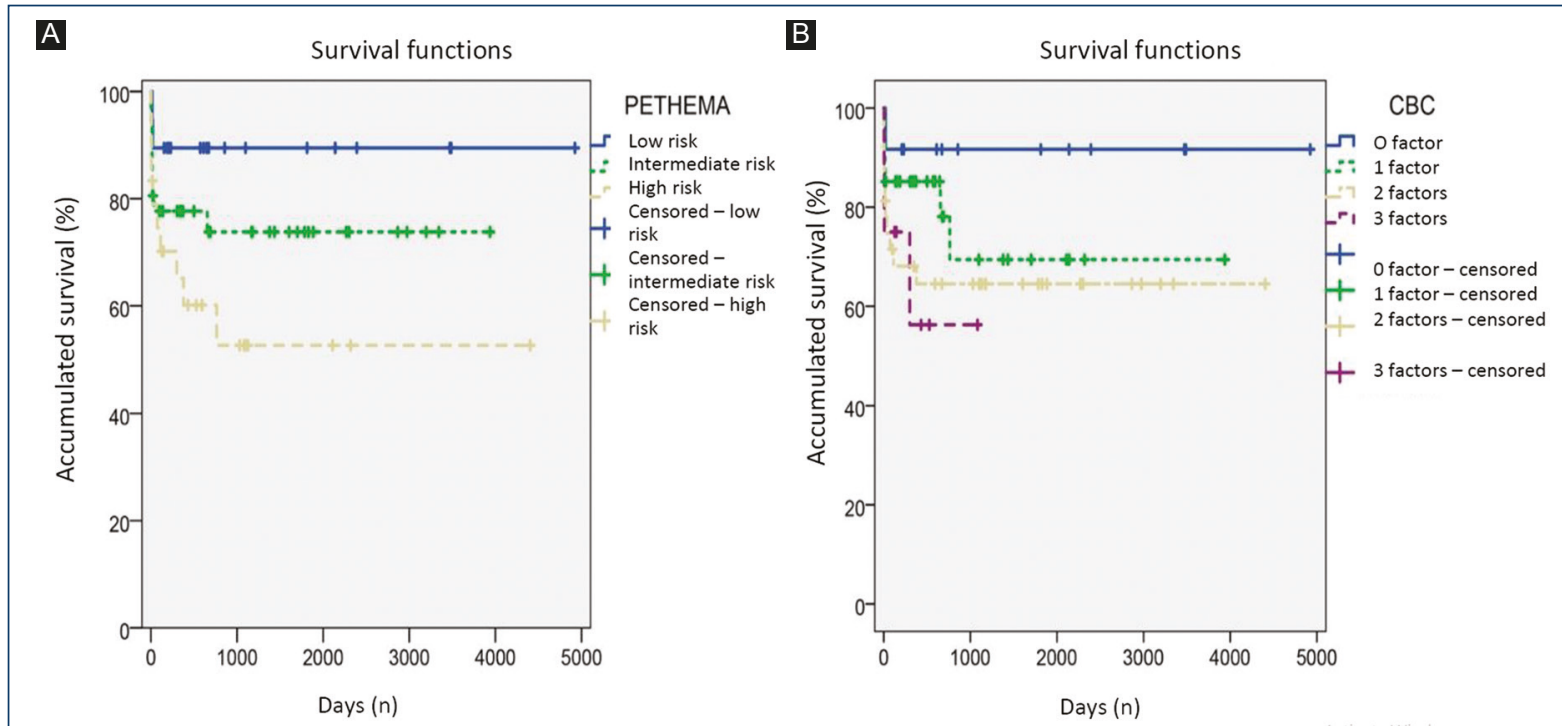

Figure 2. Overall survival of patients with acute promyelocytic leukemia according to the risk group; A: PETHEMA score; B: complete blood count score.

Table 3. Risk value for premature and late death of the different variables

\begin{tabular}{|l|c|c|c|c|}
\hline Variable & Risk group & p value & $\begin{array}{c}\text { Mortality OR } \\
\text { (confidence interval at 95\%) }\end{array}$ & $\begin{array}{c}\text { 30-day mortality OR } \\
\text { (confidence interval at 95\%) }\end{array}$ \\
\hline Hemoglobin & $<8 \mathrm{~g} / \mathrm{dL}$ & 0.0739 & $2.5731(0.9127-7.2543)$ & $0.8425(0.2819-2.5177)$ \\
\hline Leukocytes & $>10 \times 10^{9} / \mathrm{L}$ & 0.2822 & $0.5581(0.1928-1.6157)$ & $1.3333(0.4282-4.1519)$ \\
\hline Platelets & $<40 \times 10^{9} / \mathrm{L}$ & 0.0747 & $3.3694(0.8858-12.8167)$ & $0.6007(0.1742-2.0717)$ \\
\hline TT & $>27 \mathrm{~s}$ & $0.0352^{*}$ & $3.3629(1.0939-12.1316)$ & $1.4074(0.4775-4.1478)$ \\
\hline PT & $>14 \mathrm{~s}$ & 0.1583 & $2.2588(0.7282-7.0067)$ & $1.5158(0.4744-4.8436)$ \\
\hline aPTT & $>26 \mathrm{~s}$ & 0.6372 & $1.5652(0.3947-6.2063)$ & $2.3765(0.7799-7.2420)$ \\
\hline Fibrinogen & $>350 \mathrm{~g} / \mathrm{dL}$ & $0.0130^{*}$ & $3.8077(1.3250-10.921)$ & $3.5250(1.1550-10.7577)$ \\
\hline PETHEMA score & High risk & 0.053 & $7.7727(0.9668-62.4879)$ & $2.8333(0.5851-13.7203)$ \\
\hline CBC score & High risk (2-3 points) & 0.113 & $10.1485(0.5737-179.5231)$ & $3.4510(0.4131-28.8311)$ \\
\hline
\end{tabular}

${ }^{*}$ Considering $p \leq 0.05$ as statistically significant.

PT: prothrombin time; aPPT: activated partial thromboplastin time; TT: thrombin time; CBC: complete blood count.

scores 1 and 2 in the CBC scale. The upper section of table 2 is extremely important to understand this point: two-thirds of the analyzed population (64.6\%) had hemoglobin values below the cutoff point for the CBC scale; thus, placing this majority at least at intermediate risk. By integrating leukocyte and platelet values, this score is increased, which explains that for the CBC score, half of the patients had a high risk $(50.6 \%)$, while only one-third of patients were at high risk $(30.4 \%)$ in the PETHEMA score, as the latter scale considers only the leukocyte count alone to stratify patients as high risk.
These findings are similar to those presented by Loglisci et al. when reclassifying cases according to the CBC score. Among the cases identified as intermediate and high risk ( $n=66$ and $n=33$ ), while reclassifying them according to the CBC score, most patients were identified as high-risk score $1(n=60)$ and score 2-3 $(n=47)^{24}$. When analyzing the different factors individually, thrombocytopenia severity was associated with mortality (OR 3.369, $p=0.07$ ) as expected. This finding is similar to other series, in which the platelet count at the time of diagnosis is a determinant for hemorrhagic complications during the first 
4 weeks of diagnosis ${ }^{25}$. Another risk factor that was identified for death was the level of fibrinogen. Recently, Hassan et al. identified that low levels of fibrinogen $(<1.5 \mathrm{~g} / \mathrm{L})$ were associated with a high risk of premature death ${ }^{26-28}$. These, in conjunction with prolonged hemostasis, are other factors to be considered at the time of diagnosis, especially on suspicions of a disseminated intravascular coagulation (DIC). Hence, Mitrovic et al. evaluated the usefulness of incorporating the score of the International Society on Thrombosis and Haemostasis for DIC (ISTH DC) to predict death associated with hemorrhage in 56 patients with $\mathrm{APL}^{29}$. Among the main factors were the leukocyte count ( $>20 \times 10^{\%} / \mathrm{L}$ ), the performance status using the Eastern Cooperative Oncology Group (ECOG) score $>3$, the level of fibrinogen $(<2 \mathrm{~g} / \mathrm{L})$, prothrombin time $<$ $50 \%$, and ISTH DC score $>6.29$. So far, few trials have shown that elevated fibrinogen levels also affect mortality. In this research, a value of $350 \mathrm{mg} / \mathrm{dL}$ was associated with an increased risk of premature death (OR 3.525, $p=0.013$ ). These data are similar to those reported by Wei et al., in which the presence of an elevated level of fibrinogen ( $>400 \mathrm{mg} / \mathrm{dL}$ ) was associated with an adverse prognosis in different hematological malignancies including APL ${ }^{30}$. Conversely, Mantha et al. analyzed several factors that were associated with premature death in five clinical trials that included the use of ATRA during induction. Among the 995 cases analyzed, both performance status and leukocyte count $>20 \times 10^{9} / \mathrm{L}$ were the major factors associated with premature death ${ }^{31}$.

Finally, risk stratification is also useful for identifying the efficacy of new drugs. Although the combination of ATRA with chemotherapy is still the standard treatment, the use of ATRA-ATO is especially effective in patients with low/intermediate risk ${ }^{32}$, dramatically improving hemostatic disorders ${ }^{33-35}$. However, unlike trials with ATRA, creatinine as well as performance status (ECOG) are the main factors of premature death associated with the use of $\mathrm{ATO}^{36}$.

In conclusion, the use of scores such as the CBC or PETHEMA together with individual factors, such as thrombocytopenia, allows identifying those patients with APL at risk of premature death.

\section{Funding}

The authors declare that this article was written with institutional resources of Hospital General de México.

\section{Conflicts of interest}

The authors declare that they do not have any conflicts of interest.

\section{Ethical disclosures}

Protection of human and animal subjects. The authors declare that no experiments were performed on humans or animals for this study.

Confidentiality of data. The authors declare that they have followed the protocols of their work center on the publication of patient data.

Right to privacy and informed consent. The authors declare that no patient data appear in this article.

\section{References}

1. Adams J, Nassiri M. Acute promyelocytic leukemia: a review and discussion of variant translocations. Arch Pathol Lab Med. 2015; 139:1308-13.

2. Corrêa de Araujo Koury L, Ganser A, Berliner N, Rego EM. Treating acute promyelocytic leukaemia in Latin America: lessons from the international consortium on acute leukaemia experience. $\mathrm{Br} \mathrm{J}$ Haematol. 2017;177:979-83.

3. Douer D, Preston-Martin S, Chang E, Nichols PW, Watkins KJ Levine AM, et al. High frequency of acute promyelocytic leukemia among latinos with acute myeloid leukemia. Blood. 1996;87:308-13.

4. Matasar MJ, Ritchie EK, Consedine N, Magai C, Neugut Al. Incidence rates of acute promyelocytic leukemia among hispanics, blacks, asians, and non-hispanic whites in the United States. Eur J Cancer Prev. 2006;15:367-70

5. Cicconi L, Lo-Coco F. Current management of newly diagnosed acute promyelocytic leukemia. Ann Oncol. 2016;27:1474-81.

6. Coombs CC, Tavakkoli M, Tallman MS. Acute promyelocytic leukemia: where did we start, where are we now, and the future. Blood Cancer J. 2015;5:e304

7. McCulloch D, Brown $\mathrm{C}$, lland $\mathrm{H}$. Retinoic acid and arsenic trioxide in the treatment of acute promyelocytic leukemia: current perspectives. Onco Targets Ther. 2017; 10:1585-601

8. Sanz MA, Montesinos P, Kim HT, Ruiz-Argüelles GJ, Undurraga MS Uriarte MR, et al. All-trans retinoic acid with daunorubicin or idarubicin for risk-adapted treatment of acute promyelocytic leukaemia: a matched-pair analysis of the PETHEMA LPA-2005 and IC-APL studies. Ann Hematol. 2015;94:1347-56.

9. Fenaux $P$, Chastang $C$, Chevret $S$, Sanz M, Dombret $H$, Archimbaud E, et al. A randomized comparison of all transretinoic acid (ATRA) followed by chemotherapy and ATRA plus chemotherapy and the role of maintenance therapy in newly diagnosed acute promyelocytic leukemia. The European APL group. Blood. 1999:94:1192-200.

10. Avvisati G, Lo-Coco F, Paoloni FP, Petti MC, Diverio D, Vignetti M, et al. AIDA 0493 protocol for newly diagnosed acute promyelocytic leukemia: very long-term results and role of maintenance. Blood. 2011;117:4716-25

11. Sanz MA, lacoboni G, Montesinos P. Conventional induction and post-remission therapy in APL: have we arrived? Best Pract Res Clin Haematol. 2014;27:33-8.

12. Rego EM, Kim HT, Ruiz-Argüelles GJ, Undurraga MS, Uriarte Mdel R, Jacomo $\mathrm{RH}$, et al. Improving acute promyelocytic leukemia (APL) outcome in developing countries through networking, results of the international consortium on APL. Blood. 2013;121:1935-43.

13. Crespo-Solis E, Contreras-Cisneros J, Demichelis-Gómez R, Rosas-López A, Vera-Zertuche JM, Aguayo A, et al. Survival and treatment response in adults with acute promyelocytic leukemia treated with a modified international consortium on acute promyelocytic leukemia protocol. Rev Bras Hematol Hemoter. 2016;38:285-90.

14. Mantha S, Tallman MS, Soff GA. What's new in the pathogenesis of the coagulopathy in acute promyelocytic leukemia? Curr Opin Hematol. 2016;23:121-6.

15. Jácomo RH, Melo RA, Souto FR, de Mattos ER, de Oliveira CT, Fagundes EM, et al. Clinical features and outcomes of 134 brazilians with acute promyelocytic leukemia who received ATRA and anthracyclines. Haematologica. 2007;92:1431-2. 
16. Undurraga MS, Puga B, Cabrera ME, Palma T, Rossle A, Vergara CG, et al. Acute promyelocytic leukemia: results of the chilean protocol LPA2000. Rev Med Chil. 2013;141:1231-9.

17. Ramos-Peñafiel C, Montaño-Figueroa E, Martínez-Tovar A Castellanos-Sinco H, Olarte-Carrillo I, Zamora-Domínguez J, et al. Experience treating acute promyelocytic leukemia at an institution in Mexico City. Rev Hematol. 2011;12:125-30.

18. Tallman MS, Altman JK. How I treat acute promyelocytic leukemia. Blood 2009;114:5126-35

19. Sanz MA, Montesinos P, Rayón C, Holowiecka A, de la Serna J, Milone $\mathrm{G}$, et al. Risk-adapted treatment of acute promyelocytic leukemia based on all-trans retinoic acid and anthracycline with addition of cytarabine in consolidation therapy for high-risk patients: further improvements in treatment outcome. Blood. 2010;115:5137-46.

20. Testa U, Lo-Coco F. Prognostic factors in acute promyelocytic leukemia: strategies to define high-risk patients. Ann Hematol. 2016:95:673-80

21. Montesinos P, Rayón C, Vellenga E, Brunet S, González J, González M, et al. Clinical significance of CD56 expression in patients with acute promyelocytic leukemia treated with all-trans retinoic acid and anthracycline-based regimens. Blood. 2011;117:1799-805

22. Park S, Lee SJ, Kim K, Jang JH, Kim DH, Lee KH, et al. Inclusion of hemoglobin level in prignostic score provides better prognostic stratification in patients with acute promyelocytic leukemia (APL). Int J Hematol. 2013;97:388-96

23. Zuckerman T, Ganzel C, Tallman MS, Rowe JM. How i treat hematologic emergencies in adults with acute leukemia. Blood. 2012;120:1993-2002.

24. Loglisci G, Minotti C, Serrao A, Molica M, Cicconi L, Saracino R, et al. Validation of a new proposed relapse risk score (CBC-score) for acute promyelocytic leukaemia. Int J Hematol. 2014;99:100-1.

25. Song YH, Peng P, Qiao C, Zhang R, Li JY, Lu H, et al. Low platelet count is potentially the most important contributor to severe bleeding in patients newly diagnosed with acute promyelocytic leukemia. Onco Targets Ther. 2017;10:4917-24

26. Hassan IB, Zaabi MRA, Alam A, Hashim MJ, Tallman MS, Kristensen J, et al. Characteristics features and factors influencing early death in acute promyelocytic leukemia; experience from united arab emirates (UAE). Int J Hematol. 2017;106:90-8.
27. de la Serna J, Montesinos P, Vellenga E, Rayón C, Parody R, León A et al. Causes and prognostic factors of remission induction failure in patients with acute promyelocytic leukemia treated with all-trans retinoic acid and idarubicin. Blood. 2008;111:3395-402.

28. Lee HJ, Kim DH, Lee S, Koh MS, Kim SY, Lee JH, et al. Analysis of factors affecting hemorrhagic diathesis and overall survival in patients with acute promyelocytic leukemia. Korean J Intern Med. 2015;30: 884-90.

29. Mitrovic M, Suvajdzic N, Bogdanovic A, Kurtovic NK, Sretenovic A, Elezovic I, et al. International society of thrombosis and hemostasis scoring system for disseminated intravascular coagulation $\geq 6$ : a new predictor of hemorrhagic early death in acute promyelocytic leukemia. Med Oncol. 2013;30:478

30. Wei Q, Niu T, Wang M, Yang J, Liu P, Yi Y, et al. A revised fibrinogen cutoff value in the chinese disseminated intravascular coagulation scoring system may provide a better prognostic value for hematological malignancies. Acta Haematol. 2017;137:132-40.

31. Mantha S, Goldman DA, Devlin SM, Lee JW, Zannino D, Collins M, et al. Determinants of fatal bleeding during induction therapy for acute promyelocytic leukemia in the ATRA era. Blood. 2017;129:1763-7.

32. Lo-Coco F, Cicconi L, Voso MT. Progress and criticalities in the management of acute promyelocytic leukemia. Oncotarget. 2017;8:99221-2.

33. Zhao W, Wang H, Wang X, Wu F, Guo W, Qu B, et al. Effects of all-trans-retinoic acid and arsenic trioxide on the hemostatic disturbance associated with acute promyelocytic leukemia. Thromb Res. 2001; 102:197-204.

34. Li X, Wang C, Chen G, Ji B, Xu Y. Combined chemotherapy for acute promyelocytic leukemia: a meta-analysis. Hematology. 2017;22:450-9.

35. Lou Y, Qian W, Meng H, Mai W, Tong H, Tong Y, et al. Long-term efficacy of low-dose all-trans retinoic acid plus minimal chemotherapy induction followed by the addition of intravenous arsenic trioxide post-remission therapy in newly diagnosed acute promyelocytic leukaemia. Hematol Oncol. 2014;32:40-6.

36. Hou J, Wang S, Zhang Y, Fan D, Li H, Yang Y, et al. Causes and prognostic factors for early death in patients with acute promyelocytic leukemia treated with single-agent arsenic trioxide. Ann Hematol. 2017;96:2005-13. 